\title{
Os graus de negação da Vontade e a liberdade na filosofia de Schopenhauer ${ }^{1}$
}

\author{
Katia Cilene da Silva Santos
}

Mestre em Filosofia pela FFLCH - USP

RESUMO: De acordo com Schopenhauer, a existência de liberdade nos atos humanos ocorre somente quando o indivíduo anula sua essência metafísica, no momento da negação da Vontade. Não obstante, o filósofo afirma a realidade concreta de graus de negação da Vontade, expressos pelas virtudes morais. Neste artigo, propomo-nos discutir a argumentação a respeito desses graus de negação da Vontade, no intuito de compreender sua relação com a liberdade.

PALAVRAS-CHAVE: Vontade, liberdade, virtudes morais.

ABSTRACT: According to Schopenhauer, the existence of freedom in human acts occurs only when the individual cancels his metaphysical essence, at the time of the denial of Will. Nevertheless, the philosopher affirms the concrete reality of degrees of denial of Will expressed by moral virtues. In this article, we propose discuss the arguments concerning these degrees of denial of the Will, in order to understand its relation to freedom.

KEY-WORDS: Will, freedom, moral virtues.

As reflexões que apresentarei fazem parte de uma pesquisa de mestrado concluída recentemente, na FFLCH-USP, sobre o problema da liberdade na filosofia de Schopenhauer. Como se sabe, Schopenhauer defende a idéia de um determinismo radical das ações humanas, ou seja, de que não existe liberdade no mundo concreto, ou fenomênico. A liberdade existe, para ele, somente enquanto algo transcendental, que só se apresenta no mundo exibindo um caráter contraditório e místico. Essa liberdade se manifesta num fenômeno único, o da negação da Vontade, quando o indivíduo deixa de afirmar seu querer, do qual é objetivação, e passa a negá-lo. Na medida em que se rompe a relação causal entre os motivos e a vontade individual, que foi suprimida, o princípio de razão suficiente deixa de imprimir sua necessidade ao fenômeno, e a ação daí resultante deixa de ser necessária e passa a ser livre.

O que me proponho a discutir é em que medida as virtudes morais, já que são expostas pelo filósofo como espécies de negação da Vontade, poderiam também ser entendidas como espécies de liberdade. Ou seja, como Schopenhauer afirma ser a negação

\footnotetext{
${ }^{1}$ Trabalho apresentado no XIV encontro nacional da ANPOF em Águas de Lindóia, em outubro de 2010.
} 
total da Vontade o único caso em que a liberdade surge no campo do fenômeno, examinarei sua argumentação em torno dos graus de negação, manifestos empiricamente pelas virtudes morais, procurando ver se poderíamos ou não falar em "graus de liberdade".

Como se sabe, a filosofia schopenhaueriana é imanente ao mundo. As respostas para todas as questões filosóficas são buscadas por ele no mundo tal como pode ser conhecido por meio do principio de razão, e tal como pode ser sentido no interior da vontade de cada um. Em relação à ética, Schopenhauer se insere na tradição filosófica que, partindo do real, apresenta e descreve os móveis da conduta, tradição que remonta aos sofistas, como por exemplo Pródico e Protágoras. Para ele, não há uma finalidade ou um ideal a ser buscado, nem o homem tende a isso por sua própria natureza, de modo que faz nenhum sentido prescrever a justiça, a virtude ou mesmo busca da felicidade. Em primeiro lugar, porque isso é inútil, em segundo porque sua filosofia pretende descobrir a chave que abre para a compreensão do que o mundo é aqui e agora.

Assim, Schopenhauer se recusa a dizer ou prescrever o modo como deve se dar o comportamento humano. Coerentemente, sua ética não se refere a um devir, isto é, não se ocupa do modo como os homens devem agir, e sim de como o fazem de fato. $\mathrm{O}$ que a filosofia deve fazer é explicar as diferentes condutas na sua relação com a moral, pois, nas palavras do filósofo,

a moral tem a ver com a ação efetiva do ser humano e não com castelos de cartas apriorísticos, de cujos resultados nenhum homem faria caso em meio ao ímpeto da vida e cuja ação, por isso mesmo, seria tão eficaz contra a tempestade das paixões quanto a de uma injeção para um incêndio ${ }^{2}$.

A ética é a mais fácil das ciências, conforme o filósofo, pois ele entende que o princípio máximo da moral está enraizado no coração de cada um, de modo que todos têm a obrigação de extrair dele regra para cada ação singular e, assim, de se "construir a si mesmo"3. A grande censura que Schopenhauer dirige à ética de Kant é, justamente, o fato de estar fundamentada em conceitos que não explicam as ações humanas factuais, mas dizem o que elas devem ser. Ele, ao contrário, parte da impossibilidade de qualquer prescrição mas entende que há, de fato, ações cujo fundamento é moral.

${ }^{2}$ M/M, II, 6, p. $48-49$.

${ }^{3}$ Ibidem, cap. III, 18, p. 157. 
Como já mencionado, as ações humanas decorrem da relação necessária entre os motivos e o caráter inato e imutável. O rompimento dessa necessidade só seria possível no momento de negação da Vontade, no qual esta se anularia e os motivos perderiam seu poder, em função da visão através do principium individuationis. Este é definido por Schopenhauer como o tempo e o espaço, na medida em que são eles que possibilitam a pluralidade simultânea ou sucessiva dos fenômenos no mundo como representação. Segundo o filósofo, a negação da Vontade só pode ocorrer integralmente, como supressão do caráter e negação da sua essência total.

No entanto, essa teoria perde sua simplicidade quando é interpretada à luz do exposto em algumas obras, principalmente em Sobre o fundamento da moral, no quarto livro de $O$ mundo como Vontade e representação e alguns capítulos dos seus Complementos, assim como dos Parerga e Paralipomena ${ }^{4}$. Em tais obras, a compaixão aparece como um contrapeso do egoísmo, afirmação da Vontade por excelência, e as virtudes morais como momentos em que o princípio de individuação se desvanece e podemos, olhando através dele, ver a identidade metafísica de tudo o que existe. Schopenhauer não usa a expressão "graus de negação da Vontade", mas afirma que a visão através do princípio de individuação ocorre em graus, nos quais se abre a perspectiva das virtudes, desde o impulso para a justiça até a caridade. Como pretendo mostrar, o fundamento de tais graus é o mesmo que o da negação total da Vontade, e a questão que então se coloca é a de saber se é possível entender as virtudes morais como "pequenas negações" que conduzem à sua negação total. Nesse sentido, Schopenhauer diz:

afirmação da Vontade de Vida, mundo fenomênico, diversidade de todos os seres, individualidade, egoísmo, ódio, maldade: tudo isto tem uma mesma raiz; e, por outro lado, mundo da coisa-em-si, identidade de todos os seres, justiça, caridade, negação da Vontade de Viver, têm também uma mesma raiz. Se, como já demonstrei suficientemente, as virtudes morais nascem da compreensão daquela identidade de todos os seres não no fenômeno, mas na coisa-em-si, na raiz de todos os seres, a ação virtuosa é um passo momentâneo pelo ponto no qual o regresso duradouro é a negação da Vontade de viver. ${ }^{5}$

\footnotetext{
${ }^{4} \mathrm{P} / \mathrm{P}$, capítulos VIII (Acerca da ética) e XIV (Contribuições à doutrina da afirmação e negação do querer-viver). WWV II/MVR II, capítulos XLV (Da afirmação da Vontade de Viver), XLVI (Sobre o nada e as dores da Vida), XLVII (Da Moral), e XLVIII (Teoria da negação da Vontade de Viver).

${ }^{5}$ WWV II/MVR II, cap. 48, "Sobre a doutrina da negação da Vontade de viver” p. 1045.
} 
De acordo com Schopenhauer o homem é o fenômeno mais acabado da Vontade, pois é capaz de um grau de conhecimento elevado que o permite repetir perfeitamente a essência do mundo sob a forma da representação. Por meio do seu espelhamento na representação humana, a Vontade pode alcançar plena consciência de si mesma. Assim, segundo o filósofo, o homem se posiciona em relação a essa autoconsciência da Vontade de dois modos distintos: ou cegamente, caso em que o conhecimento the permanece um motivo, ou esclarecendo sua essência, quando então tal conhecimento se lhe torna um quietivo, silenciando e suprimindo todo o querer ${ }^{6}$. Esses dois posicionamentos correspondem aos dois pontos de vista pelos quais o homem pode tornar-se consciente de sua própria existência, que são a intuição empírica e a visão de seu interior ${ }^{7}$. No primeiro modo de conhecimento, ele apreende apenas o fenômeno sob as condições de tempo, de espaço e das formas do princípio de razão suficiente. Enxerga a multiplicidade e a diversidade das aparências, entendendo-se como um ser limitado, finito e essencialmente distinto dos outros, sem perceber a essência única de tudo o que existe. No segundo modo, por seu turno, ao olhar para o seu interior, atenta para a identidade entre a sua essência e a dos outros, isto é, reconhece a Vontade una e indivisível em todos os fenômenos. Olhando através do princípio de individuação, percebe que a essência de todas as coisas é uma e a mesma $^{8}$.

Essas duas maneiras distintas de o homem se entender em relação ao mundo determinará a posição em que ele se colocará frente à Vontade, isto é, afirmando-a ou negando-a. O ponto de vista da afirmação parte das condições do tempo e do espaço, pelas quais se intui múltiplas coisas em momentos e lugares diferentes. Nesse modo de conhecimento, o indivíduo toma as aparências das coisas pelas próprias coisas, pelo que os fenômenos aparecem no mundo como distintos, divididos e inumeráveis ${ }^{9}$. Em virtude disso, esse indivíduo estabelece uma grande distinção entre si e o resto do mundo, e conclui que dor e prazer são realidades contrárias. Inclina-se, então, para o contentamento e os prazeres da vida, sem saber que são estes, justamente, que o ligarão às dores e aos sofrimentos. Por essa razão, o indivíduo busca seu próprio bem-estar, julgando poder livrar-se das dores e satisfazer todas as suas necessidades.

${ }^{6}$ WWV I/MVR I, § 56, p. 334.

${ }^{7}$ P/P, cap. VIII, “Acerca da ética”, § 115, p. 202.

${ }^{8}$ Ibidem, loc. cit.

WWV I/MVR I, § 63, p. 378. 
Uma vez que a Vontade, tal como definida pelo filósofo, expressa-se num querer que se esforça continuamente, sem satisfação duradoura, sua a afirmação é busca do contentamento desse querer. A Vontade preenche a vida do homem em geral e sua afirmação se dá a partir da sua objetivação no corpo. Conforme Schopenhauer, o querer individual, que se desenvolve no tempo, é a "paráfrase do corpo" 10, de forma que afirmação da Vontade e afirmação do corpo são o mesmo. Em última instância, os atos de vontade orientam-se para a conservação do indivíduo e da espécie. No dizer do filósofo,

o tema fundamental dos múltiplos atos de vontade é a satisfação das necessidades que são inseparáveis da existência do corpo em estado saudável; estas encontram nele sua expressão, e podem reduzir-se à conservação do indivíduo e à propagação da espécie ${ }^{11}$.

Embora não fale de graus de negação da Vontade, Schopenhauer menciona graus de afirmação dela, ligados à veemência com que esta afirmação se dá. Tais graus assentam-se nas variáveis intensidades dos desejos, que podem manifestar-se como leves afetos ou até paixões violentas, nas quais o indivíduo não somente afirma a própria existência, mas nega a dos outros, buscando suprimi-las caso sejam obstáculos à sua vontade ${ }^{12}$. Além da diferença de veemência das vontades individuais, há os dois graus fundamentais de afirmação já mencionados, presentes em todo o gênero humano. O primeiro e mais fraco é a autoconservação do indivíduo, que afirma a vida de um fenômeno singular; o segundo e mais forte é o impulso sexual, que afirma a vida de toda uma espécie.

Com efeito, segundo Schopenhauer, a natureza não se preocupa com a duração dos frágeis indivíduos, deixando-os sucumbir aos milhares, mas cuida somente da perpetuação da espécie por meio do inexpugnável impulso sexual ${ }^{13}$. Este vai além da afirmação da existência do indivíduo, que preenche um tempo curto, e afirma a vida por tempo indeterminado, ultrapassando a morte individual. Nisso, diz o filósofo, aparece claramente a decidida afirmação da Vontade na natureza, por meio da qual as espécies viventes ligam-se a um todo, na medida em que o ato sexual gera uma nova vida que é diferente do procriador apenas no fenômeno, mas em si mesma é idêntica a ele ${ }^{14}$. $\mathrm{O}$ ato sexual, nesse

\footnotetext{
${ }^{10}$ Ibidem. $\S 60$, p. 353.

${ }^{11}$ Ibidem, loc. cit.

${ }^{12}$ Ibidem, § 59, p. 354.

${ }^{13}$ WWV II/MVR II , cap. 47, “Sobre a ética”, 1037.

${ }^{14}$ WWV I/MVR I, $\S 60$, p. 354.
} 
sentido, é o "ovo do mundo" 15 , é o que expressa mais claramente a essência da Vontade. Sintomaticamente, diz Schopenhauer, apenas por meio dele se dá a entrada na vida de animais e de homens. Como ele afirma,

o ato da geração é para o mundo o que a palavra é o para o enigma. $\mathrm{O}$ mundo é extenso no espaço e velho no tempo, e contém uma multiplicidade inesgotável de formas. Não obstante, tudo isso é somente fenômeno da Vontade de Vida; e a concentração, o foco dessa Vontade é o ato da geração. Este ato é, portanto, aquilo em que mais claramente se expressa a essência íntima do mundo ${ }^{16}$.

Portanto, a autoconservação é o primeiro e mais fraco esforço do indivíduo em sua afirmação da Vontade, pois conserva vivo o corpo de um exemplar da espécie. Tão logo assegurada a conservação individual, diz Schopenhauer, o homem passa a seguir a essência íntima da natureza e empenha-se pela propagação da espécie. O impulso sexual, além disso, evidencia a independência da Vontade em relação ao conhecimento, pois, nas palavras do filósofo, “os genitais são o verdadeiro foco da vontade, e portanto, o pólo oposto do cérebro, que representa o conhecimento, isto é, o mundo como representação" ${ }^{17}$.

No modo de ação que se orienta para a afirmação da Vontade, o indivíduo parte da compreensão do mundo e de si mesmo pelo princípio de razão suficiente, compreensão que é a mesma base do egoísmo. Embora o egoísta tenha em torno de si sua própria essência inúmeras vezes repetida, só é capaz de vê-la em seu interior, e sente que toda a natureza exterior existe apenas na sua representação. Como ocorre em todos os indivíduos, a Vontade encontra-se por inteiro no egoísta que, por isso, entende-se como o centro do universo, antepondo a própria existência e bem-estar a tudo o mais. Assim, o indivíduo egoísta é consciente dos outros de maneira mediata, como algo dependente de seu próprio ser e existência, enquanto a si mesmo conhece como o em-si do mundo, a condição complementar do mundo como representação ${ }^{18}$. Caso se mostrasse necessário, aniquilaria qualquer pessoa ou o próprio mundo para conservar-se por mais tempo. Através do egoísmo, afirma o filósofo, a Vontade mostra um conflito interno consigo mesma, cuja base

\footnotetext{
${ }^{15}$ WWV II/MVR II , cap, 45, “Sobre a afirmação da Vontade de viver", p. 1008.

${ }^{16}$ Ibidem, p. 1007.

${ }^{17}$ WWV I/MVR I, $\S 60$, p. 356.

${ }^{18}$ Ibidem, $\S 61$, p. 358.
} 
e essência está na oposição entre o indivíduo como microcosmo e o macrocosmo em que se insere. Assim, diz ele,

é o egoísmo que nos revela de um modo terrível o conflito interno da Vontade consigo mesma. Pois o egoísmo deve sua permanência e sua essência à mencionada oposição entre o microcosmo e o macrocosmo, ou a que a objetivação da Vontade tem como forma o principium individuationis e, por isso, a Vontade se manifesta da mesma maneira em inumeráveis indivíduos, e em cada um deles íntegra e completamente em seus dois aspectos (vontade e representação) ${ }^{19}$.

Por conseguinte, enquanto cada um é dado a si mesmo imediatamente como Vontade inteira, os outros seres lhes são dados meramente como representações. Em função disso, o ser e a conservação próprios são antepostos a todos os outros em conjunto.

Conforme essa argumentação, somos inclinados para a injustiça e para a violência pela nossa própria constituição, pois ela é fundada sobre egoísmo, necessidades e anseios, presentes imediatamente à consciência. A Vontade expõe a auto-afirmação do corpo em inumeráveis indivíduos lado a lado, e o egoísmo inerente a todo ser vivo conduz, fatalmente, à negação da mesma Vontade que aparece em outro indivíduo, gerando o bellum omnium contra omnes ${ }^{20}$. A injustiça, assim, é um conceito positivo, na medida em que é uma ação que ofende a vontade de outrem, ou seja, que causa dano à pessoa, à liberdade, à propriedade ou à honra de alguém ${ }^{21}$. A prática da injustiça, nesse sentido, é a afirmação veemente da Vontade num fenômeno, ultrapassando os limites do próprio corpo e de suas forças a ponto de negar a mesma Vontade que se manifesta em outro. Em razão dessa veemência, a Vontade entra em conflito consigo mesma, "cravando os dentes na própria carne" ${ }^{22}$. A injustiça, desse modo, é onipresente, definindo-se como invasão dos limites da afirmação da Vontade alheia.

Segundo penso, essa explanação sobre a afirmação da Vontade é necessária para a compreensão da sua negação. No capítulo XIV de Parerga e Paralipomena, intitulado “Contribuições à doutrina da afirmação e da negação do querer viver”, Schopenhauer esclarece que a negação da Vontade não significa a eliminação de uma substância, mas o

\footnotetext{
${ }^{19}$ Ibidem, loc. cit.

20 “Guerra de todos contra todos”. Ibidem. $\S 61$, p. 359.

${ }^{21} \mathrm{M} / \mathrm{M}, \mathrm{III}, 17, \mathrm{p} .142-143$.

${ }^{22}$ WWV I/MVR I, $\S 70$, p. 429.
} 
simples ato do não-querer. De acordo com ele, afirmação e negação da Vontade manifestam-se como Velle et Nolle em um e o mesmo sujeito, de forma que este não será destruído se houver a substituição de uma pela outra ${ }^{23}$. A negação da Vontade desenvolve-se como um "não-querer" que contradiz o querer individual, isto é, vai contra a sua afirmação. Nesse sentido, relaciona-se às virtudes morais, entendidas como inibição ou negação das potências antimorais do egoísmo e da injustiça, nascidos da afirmação da Vontade. Como já mencionado, a ação virtuosa representa a produção momentânea de um estado que, quando se estabelece definitivamente, constitui a negação total da Vontade. Assim, como afirma o filósofo, "a ausência de toda motivação egoísta é, portanto, $o$ critério de uma ação dotada de valor moral" ${ }^{24}$, pois se trata de uma ação em que, embora tivesse a inclinação, a vontade individual nega-se a invadir os limites da vontade de outro indivíduo. Em suma, a virtude moral procede do mesmo conhecimento que leva à negação completa da Vontade, a saber, o conhecimento imediato e intuitivo da identidade metafísica de todos os seres, da visão através do princípio de individuação.

A primeira virtude, que aparece em menor grau, é a justiça. Schopenhauer a define como sendo negativa, como negação do conceito de injustiça, que é o originário e positivo. A ação justa não ultrapassa o limite que leva à negação da vontade alheia, e o homem justo é aquele que não inflige sofrimento a outrem para aumentar seu bem-estar, não comete crimes e respeita o direito e a propriedade dos outros ${ }^{25}$. De acordo com o filósofo, o modo de ação do justo mostra que o princípio de individuação não é uma barreira absoluta, como no caso do injusto, pois aquele

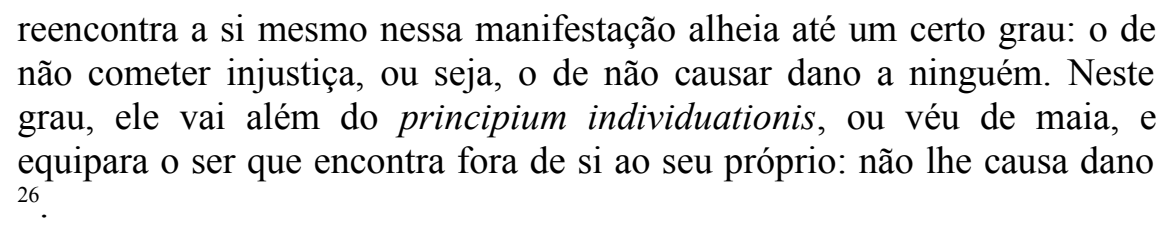

Portanto, o homem justo suprime em certa medida a diferença que o princípio de individuação estabelece entre si e o outro, inibindo seu egoísmo e recusando-se a causar-lhe sofrimento.

\footnotetext{
${ }^{23} \mathrm{P} / \mathrm{P}$, cap. XII, “Contribuições à doutrina da afirmação e da negação do querer viver”, § 161, p. 227.

${ }^{24} \mathrm{M} / \mathrm{M}, \mathrm{III}, 15$, p. 124.

${ }^{25}$ WWV I/MVR I, $\S 66$, p. 396.

${ }^{26}$ Ibidem, § 66, p. 396.
} 
O segundo grau de negação da Vontade é a caridade desinteressada, na qual o véu de maia se torna transparente e a ilusão do princípio de individuação se dissipa. O indivíduo caridoso reconhece a sua vontade em cada ser que existe e sofre, a ponto de se identificar completamente com a dor de um outro. Conforme o filósofo, "ser curado dessa ilusão e engano do véu de maia e praticar obras de amor são uma e mesma coisa. $\mathrm{O}$ amor é um sintoma inconfundível desse conhecimento" ${ }^{27}$. A compaixão é o que está na base tanto da justiça quanto da caridade e identifica completamente o indivíduo compassivo com o sofredor, suprimindo a barreira entre o "eu" e o "não-eu" ${ }^{28}$. Não se trata de um conhecimento abstrato, refletido, mas de uma participação imediata na dor alheia, pela qual o indivíduo não apenas se recusa a causar dano a outrem, como o justo, mas é impelido à caridade. Nesse sentido, Schopenhauer afirma que a caridade é algo místico, em contradição com o mundo fenomênico. Nas suas palavras,

podemos considerar as ações que lhe são concordes, por exemplo, a caridade, como o início da mística. Toda caridade realizada com motivação pura revela que aquele que a efetua, em clara contradição com o mundo fenomênico, no qual o indivíduo estranho se dispõe inteiramente separado dele, com o mesmo se reconhece idêntico. Assim, toda caridade totalmente desinteressada constitui uma ação misteriosa, um mistério: por esse motivo, a tentativa de justificá-la foi obrigada a se refugiar em muitas ficções ${ }^{29}$.

Assim, a compaixão inclina o homem a sentir em si mesmo as dores que correspondem a outro. Ela significa, além disso, um desapego à vida e aos prazeres, de maneira que a obediência e o cumprimento das leis morais, fundadas na compaixão, teria por conseqüência uma vida de pobreza, privações, trabalhos e dores ${ }^{30}$. Dessa forma, diz Schopenhauer, "a justiça é o cilício que mortifica continuamente a quem a pratica, e a caridade, que se priva do necessário, é um jejum perpétuo" ${ }^{31}$. Por conseguinte, as virtudes morais são resultado de um traspassamento do princípio de individuação e significam um reconhecimento da essência idêntica de todos os fenômenos. São um primeiro indício de

\footnotetext{
${ }^{27}$ Ibidem, § 66, p. 399.

${ }^{28} \mathrm{M} / \mathrm{M}, \mathrm{IV}, 22$, p. 201-202.

${ }^{29}$ P/P, cap. VIII, “Acerca da ética”, § 115, p. 201.

${ }^{30}$ Ibidem, loc. cit.

${ }^{31}$ WWV II/MVR II , cap. 48, “Sobre a doutrina da negação da Vontade de viver” p. 1043.
} 
que o indivíduo não está totalmente atado às aparências, e constituem um estímulo para a renúncia e a negação total da Vontade $^{32}$.

Todavia, as virtudes não são o fim último da moral, mas apenas graus que conduzem à negação total da Vontade. Para que o fím seja alcançado, é necessário que a visão através do princípio de individuação seja elevada ao mais alto grau de distinção. O homem que assim procede, diz o filósofo, toma para si todas as dores do mundo, todos os tormentos, e sente todos os seres próximos a si. Trata-se do asceta que, vendo o mundo em esforço, sofrimento e perecimento constantes, não procura satisfazer a Vontade, pois compreende que afirmá-la é o mesmo que reiterar a existência repleta de dores. Esse conhecimento do todo e da essência das coisas permite-lhe reconhecer tanto os prazeres quanto as dores na afirmação da Vontade e torna-se um quietivo para sua volição, levando-o ao estado de voluntária renúncia, resignação e serenidade ${ }^{33}$.

Assim, diz Schopenhauer, a negação total é prenunciada pela transição da virtude à ascese, que vai além do amor aos outros e da justiça, provocando uma repulsa pela própria essência da Vontade. Em suas palavras,

o processo em que se dá a conhecer esta transformação é a transição da virtude à ascese. Já não lhe basta amar as outras pessoas como a si mesmo nem fazer por elas tanto quanto por si, mas nasce nele uma aversão a esse ser cuja expressão é seu próprio fenômeno, a Vontade de viver, núcleo e essência de um mundo considerado como um tormento ${ }^{34}$.

O asceta renega a Vontade tal como aparece no seu fenômeno, ou seja, no seu corpo, contradizendo-a com seus atos. Procurando estabelecer em si uma indiferença a tudo, contradiz o corpo negando, em primeiro lugar, o impulso sexual. A castidade, ao bloquear a afirmação que vai além da vida individual, determina que a Vontade se suprima juntamente com a morte do corpo. Além da castidade, a pobreza voluntária, a alimentação módica, a autopunição e a autoflagelação também representam exercícios ascéticos e servem de mortificação contínua para a Vontade.

A ascese leva a um estado brando de ânimo, em que o indivíduo não reage à injustiça sofrida, por considerar todo sofrimento como ocasião para negar a Vontade. Nesse

\footnotetext{
${ }^{32}$ Ibidem, p. 1042.

${ }^{33}$ WWV I/MVR I M., $\S 68$, p. 405.

${ }^{34}$ Ibidem, $\S 68$, p. 405.
} 
caso, diz o filósofo, quando a morte chega, não apenas o fenômeno finda, mas ocorre uma redenção e a própria essência do indivíduo é suprimida: o mundo acaba ao mesmo tempo ${ }^{35}$. É uma remissão, uma verdadeira salvação, já que “com ela não acaba, como em outras pessoas, o fenômeno, mas é a essência mesma o que foi suprimido, a essência que aqui só tinha uma débil existência em e pelo fenômeno; e essa última débil ligação se rompeu também" 36 .

Como já dito, o conhecimento do qual procede a negação da Vontade é intuitivo e não encontra perfeita expressão em conceitos. Sua manifestação está nos atos dos santos e ascetas das religiões cristã, hindu e budista, cujas experiências de vida são exemplos de negação da Vontade. Na conduta de tais pessoas, diz Schopenhauer, evidencia-se a negação completa de sua essência, bem como o conhecimento como quietivo do querer e a liberdade no fenômeno. A ascese, portanto, configura-se como a contradição proposital da vontade individual pela recusa do agradável e a busca do desagradável, por meio da castidade e da penitência $^{37}$.

Em diversos momentos de suas obras, Schopenhauer associa a liberdade à negação total da Vontade, isto é, à conduta santa, afirmando que é o único caso em que aquela aparece no fenômeno. Não obstante, de acordo com ele, o fundamento da negação total da Vontade - a visão através do princípio de individuação - é o mesmo que o das virtudes morais, nas quais a visão se dá de forma ascendente, desde a justiça até a extinção de todo o querer. Poderíamos concluir que, assim como há graus de negação da Vontade, manifestos na vida concreta, há também graus de liberdade, que igualmente se verificariam na vida fenomênica? De fato, Schopenhauer constantemente enfatiza a necessidade que concerne a cada uma das ações, as quais só podem ocorrer no mundo fenomênico e ser, portanto, conseqüências de motivos dados na experiência. Mais ainda, conforme sua filosofia, o conteúdo inteiro da natureza e o conjunto completo de seus fenômenos são absolutamente necessários. No entanto, como ele afirma, a vontade do asceta entra em contradição consigo mesma ao negar o que o seu fenômeno expressa, ao mesmo tempo em que continua existindo como corpo dotado de vida. Assim, como um ser existente, o asceta representa a contradição real que surge da intervenção imediata da Vontade em si na necessidade do

\footnotetext{
${ }^{35}$ Ibidem, $§ 68$, p. 408.

${ }^{36}$ Ibidem, loc. cit.

${ }^{37}$ Ibidem, $§ 68$, p. 417.
} 
fenômeno, e seus atos são, ao mesmo tempo, determinados e livres. Determinados, porque se dão na experiência, e livres, porque ao negar a Vontade, quebram a cadeia causal que liga motivo e caráter. O mesmo, todavia, poderia ser dito a respeito das virtudes morais que, ao contraporem o egoísmo, essência íntima de todo vivente, estariam se opondo à afirmação da vontade do indivíduo. Ou seja, romperiam também, de alguma forma, aquela conexão causal estrita.

Em Sobre o fundamento da Moral, Schopenhauer apresenta três motivações fundamentais para as ações humanas, que são o egoísmo, a maldade e a compaixão ${ }^{38}$. Esta última, segundo o filósofo, enquanto fundamento moral genuíno, está presente em todo homem, mesmo no mais cruel, tanto quanto o egoísmo. Assim como a compaixão tem existência factual, é forçoso que o grau de negação da Vontade que ela representa também tenha. Com efeito, Schopenhauer afirma que os atos surgidos da compaixão, como a caridade autêntica, constituem também uma contradição nítida com o mundo fenomênico, pelo que o filósofo a chama de "ação misteriosa", do mesmo modo como a liberdade que, citando Malebranche, ele afirma ser um mistério. Embora a negação da Vontade tenha que se dar em relação à essência total do indivíduo, já que o caráter não muda parcialmente, acaso possamos falar em pequenas supressões do querer. Com isso teríamos de falar também de pequenas liberdades ou talvez liberdades momentâneas, nas quais a visão do princípio de individuação determina a Vontade a se exteriorizar em sentido oposto ao da afirmação, como seria o esperado. Entretanto, não estamos autorizados a afirmar cabalmente que as ações virtuosas são livres, pois Schopenhauer jamais se refere a elas como tal. Ele reserva a liberdade unicamente à aniquilação total da Vontade, pois somente quando esta fosse suprimida os motivos não fariam mais efeito. Destarte, as virtudes morais são contradições da vontade individual, na medida em que se opõem à afirmação, mas elas não excluem toda motivação, o que só ocorre na negação completa. Assim, junto-me à professora Maria Lúcia Cacciola quando aponta que a ação moral pode ser entendida como sendo livre sob um aspecto, e condicionada, sob outro. Nas palavras dela,

[...] o ato compassivo, apesar de estar fundamentado metafisicamente no reconhecimento da essência comum, manifesta-se ainda por meio de um motivo que é a representação do outro e do seu sofrimento. Neste sentido, como manifestação do caráter empírico, a ação compassiva não é livre,

\footnotetext{
${ }^{38} \mathrm{M} / \mathrm{M}, \mathrm{III}, 16$, p. 130-131.
} 
mas condicionada por um motivo. No entanto, já que o caráter inteligível é a própria vontade como essência de cada indivíduo, essa ação pode, por outro lado, ser considerada livre enquanto participa da natureza da Vontade. Assim, a natureza humana apresenta-se como sendo capaz de ações que têm valor moral, o que indica que ela não é apenas "má", contradizendo de certo modo a natureza da Vontade como fonte de todo sofrimento e dor e introduzindo um sentido moral no mundo ${ }^{39}$.

\section{Referências bibliográficas}

\section{Obras de Schopenhauer}

SCHOPENHAUER, A. Sämtliche Werke. 7 Bände, Wiesbaden, F. A. Brokhaus, 1972, edição de A. Hübscher.

. De la cuadruple raiz del principio de razon suficiente. Trad. de Leopoldo-Eulogio Palácios, Madrid: Editorial Gredos, 1981.

. De la volonté dans la nature. Trad. de E. Sans, Paris: PUF, 1996.

. El Mundo como Voluntad y Representación. Trad. de Rafael-José Fernández y M. ${ }^{\mathrm{a}}$ Montserrat Armas Concepción, Madrid: Akal Editores, 2005.

. El Mundo como Voluntad y Representación: Volumen segundo, que contiene los complementos a los quatro livros del primeiro volumen Trad. de Rafael-José Fernández y M. ${ }^{\mathrm{a}}$ Montserrat Armas Concepción, Madrid: Akal Editores, 2005.

. Los dos problemas fundamentales de la ética. Trad. de Pilar López de Santa Maria, $1^{a}$ ed., Madrid: Siglo XXI, 1993.

. O mundo como vontade e representação, parte III; Crítica da filosofia kantiana; Parerga e paralipomena, cap. V, VIII, XII, XVI. Trad. de Wolfgang Leo Maar e Maria Lúcia M. O. Cacciola, São Paulo: Victor Civita, 1985 (Os pensadores).

. Parerga y paralipomena I, II e III. Trad. Antonio Zozaya. Málaga: Agora, 1997.

. Sobre o fundamento da moral. Trad. de Maria Lúcia M. O. Cacciola $1^{\mathrm{a}}$ ed., Martins Fontes, São Paulo, 1995.

\section{Outras obras}

ADORNO, T; HORKHEIMER, M. Sociológica. Madrid, Taurus, 1971.

${ }^{39}$ CACCIOLA, M. L. Schopenhauer e a questão do dogmatismo, São Paulo: Edusp/Fapesp, 1980, p. 160. 
ARAMAYO, R. R. Para leer a Schopenhauer. Madrid: Aliança Editorial, 2001.

BARBERA, S. Une philosophie du conflit. $1^{\mathrm{a}}$ ed., Paris: PUF, 2004.

BARBOZA, J. A decifração do enigma do mundo. São Paulo: Moderna, 1997. (Coleção Logos).

BARBOZA, J. A metafísica do belo em Arthur Schopenhauer. São Paulo: Humanitas/FFLCH-USP, 2001.

BRANDÃO, E. O Conceito de Matéria na obra de Schopenhauer. Tese (Doutorado). Faculdade de Filosofia, Letras e Ciências Humanas. Universidade de São Paulo, São Paulo, 2003.

BRÉHIER, E. Histoire de la philosophie allemande. $3^{\mathrm{a}}$ ed., Paris: VRIN, 1954.

BRUM, J. T. O pessimismo e suas vontades: Schopenhauer e Nietzsche. Rio de Janeiro: Rocco, 1998.

CACCIOLA, M. L. A crítica da razão no pensamento de Schopenhauer. Tese (Mestrado) Faculdade de Filosofia, Letras e Ciências Humanas. Universidade de São Paulo, São Paulo, 1981.

. Schopenhauer e a questão do dogmatismo, São Paulo: Edusp/Fapesp, 1980.

$\overline{78-98 .}$

“A questão do finalismo na filosofia de Schopenhauer". Discurso, n 20, 1993:

CASSIRER, E. El problema del conocimiento III. Trad. de Wenceslao Roces, $4^{\mathrm{a}}$ reimpr., México: Fondo de Cultura Económica., 1993.

. Kant vida y doctrina. Trad. de Wenceslao Roces, $1^{\mathrm{a}}$ ed., $6^{\mathrm{a}}$ reimpr., México: Fondo de Cultura Econômica, 2003.

COLOMER, E. El pensamiento alemán de Kant a Heidegger. Tomo segundo. $2^{\mathrm{a}}$ ed., $3^{\mathrm{a}}$ reimp., Barcelona: Herder, 2006.

DELEUZE, G. A filosofia crítica de Kant. Trad. de Germiniano Franco, Lisboa: Edições $70,2000$.

FILHO, Rubens R. T. Ensaios de filosofia ilustrada. 2a ed., São Paulo: Iluminuras, 2004.

HORKEIMER, M. "O pensamento de Schopenhauer em relação à ciência e à religião". Comentário e tradução de Flamarion Caldeira Ramos. In: Cadernos de Filosofia Alemã, XII, jul-dez. 2008, p. - 128.

KANT, I. Crítica da Razão Pura. Trad: de Manuela Pinto dos Santos e Alexandre Fradique Morujão. Lisboa: Fundação Calouste Gulbenkian, 1985. 
. Crítica da Razão Prática. Trad. de Valério Rohden.1 ${ }^{\mathrm{a}}$ ed., São Paulo: Martins Fontes, 2003.

. Crítica da Faculdade do Juizo. Trad. Valério Rohden e António Marques. $1^{\mathrm{a}}$ ed., Rio de Janeiro: Forense Universtária, 1993.

. Duas introduções à Crítica do Juízo. Trad. Rubens Rodrigues Torres Filho et al. ${ }^{\mathrm{a}}$ ed., São Paulo: Iluminuras, 1995.

KÜLPE, O. Kant. Trad. de Domingo Miral López. 3ª ed., Barcelona: Labor S.A., 1939.

LEFRANC, J. Compreender Schopenhauer. Trad. de Ephraim Ferreira Alves. Petrópolis: Vozes, 2005.

PASCAL. G. O pensamento de Kant. Trad. de Raimundo Vier, $7^{\mathrm{a}}$ ed., Petrópolis: Vozes, 2001.

PERNIN, M-J. Schopenhauer: decifrando o enigma do mundo. Trad. de Lucy Magalhães. Rio de Janeiro: Jorge Zahar Editor, 1995.

PHILONENKO, A. Una filosofía de la tragédia. Trad. de Gemma Muñoz-alonso López. $1^{\mathrm{a}}$ ed., Barcelona: Antropos, 1989.

RAYMOND, D. Schopenhauer. $1^{\text {a }}$ Ed., SEUIL, 1995.

RIBOT, T. La philosophie de Schopenhauer. 14ª ed., Paris: Félix Alcan, 1925.

SALLES, J.C. (Org.). Schopenhauer e o Idealismo Alemão. Salvador: Quarteto, 2004.

Recebido: 05/09/10

Received: 09/05/10

Aprovado: $25 / 11 / 10$

Approved: 11/25/10 